\title{
The Role of Microbiota in Manifestation of Extrusion Food Products' Side Effects
}

\author{
Rubakhova Valentina ${ }^{1}$, Zamaro Alexandra ${ }^{1}$, Grinchik Nikolay ${ }^{2}$, Larchenko Maria ${ }^{1}$, Koulchitsky Stanislav ${ }^{3}$, Loiko \\ Diana ${ }^{1}$, Derevyanko Irina ${ }^{1}$, Sushko Timur ${ }^{1}$, Chuprina Alesya ${ }^{1}$, Kuznetsova Tatiana ${ }^{1}$, Stukach-Takalchyk Yuliya ${ }^{1}$, \\ Derevyanko Marina $^{1}$ and Kulchitsky Vladimir*1 \\ ${ }^{1}$ Institute of Physiology, National Academy of Sciences, Minsk, Belarus, Europe
}

${ }^{2}$ AV Luikov Heat and Mass Transfer Institute, National Academy of Sciences, Minsk, Belarus, Europe

${ }^{3}$ Liege University, Liege, Belgium, Europe

Received: 沑: July 24, 2018; Published: 制 July 31, 2018

*Corresponding author: Vladimir Kulchitsky, MD, Dr. Sci. Professor Scientific Director, Institute of Physiology National Academy of Sciences of Belarus, 28 Akademicheskaya Street, Minsk 220072, Belarus

\section{Introduction}

Significance of various types of diets for the organism in health and disease is well known. For example, Mediterranean diet is usually associated with longevity of Mediterranean region inhabitants. On the other hand, intake of poor-quality food products is accompanied with development of acute and chronic diseases of gastrointestinal tract. Therefore, it is understandable why ancient doctors used to place emphasis on diets. Nowadays these beliefs evolved into scientific fields substantiating importance of diets' heat value, optimal content of proteins, fats, carbohydrates, vitamins, minerals, etc. Unfortunately, the increase of knowledge in this scientific area is accompanied with the growth of morbidity, which is directly or indirectly connected with intake of food products; also medical expenses on treatment of these patients grow [1,2]. The search for "morbidity quality food intake" revealed 2460 articles in PubMed on July 21, 2018. The authors have chosen contentious topic among the range of problems in this field: the functional significance of extrusion food products in the scope of increasing consumer interest, especially in children and teens.

\section{Extrusion Food Products}

Scientific articles adduce both pros [3] and cons [4] of extrusion food products intake. For example, there are evidences that experimental rats died in two weeks after consumption of food based on extrusion products. The assumption about toxic products in food [4] seems impossible. Strange, but that social problem generates mild interest. The search for "extrusion food prospects" revealed one article in PubMed on July 21, 2018 [3], but "extrusion food side effects" 62 articles. The articles about side effects describe lowering of free lysine in extruded samples [5], change of their physical and chemical properties [6], ochratoxin A transformation [7] and structural changes in mycotoxins [8]. Therefore, the facts speak for presence of side effects after intake of existent extrusion food products.

\section{Consequences of Extrusion Food Consuming: Experimental Analysis}

Above mentioned became stimulus to verify hypothesis on the mechanisms of negative effects development up to lethal outcomes [4] during regular intake of extrusion food products. Male Wistar rats $(\mathrm{n}=15)$ weighing $173.6 \pm 11.7 \mathrm{~g}$ were divided into three equal groups in pilot project. Animals from the first group received standard food ration, the ones from the second group - the same amount of ration consisting of extrusion products (dry cereal breakfast, confectionary "Matyash", Tula, Russian Federation). The animals from the third group received the 1:1 mixture of two above mentioned rations. All the animals were kept in equal standard vivarium conditions. Mann-Whitney test revealed statistically significant $(\mathrm{p} \leq 0.01)$ decrease in body mass of rats receiving extrusion food products only in one and two weeks after beginning of the experiment compared to other groups. In fact, the mass of animals in the second group did not differ from the baseline. The experiment with different types of rations was finished at this stage and all the animals began receiving standard food ration. Body mass of all the rats did not differ statistically in two weeks after transfer to standard food ration.

Elevated Plus Maze (program ANY-maze, Stoelting Inc., USA) test revealed decrease in maximal speed and distance covered in closed zone together with decrease of mobility time in closed zone in two weeks after beginning of the experiment in rats with extrusive nutrition. These rats also showed statistically significant $(p \leq 0.05)$ differences in the amount of immobile episodes in closed zone and average speed in open zone compared to their results 
before the experiment. Eventually, rats from the second group became less active in closed zone and showed decreased movement speed in both open and central maze zones.

Cognitive functions and central control of locomotor functions changed - that fact was established and it was decided to finish the experiment. One rat was chosen from each group in order to analyze brain structural features. Series of horizontal slices $8 \mu \mathrm{m}$ in thickness was made using freezing microtome "Microm HM525" (Germany). The Figure 1 from the right side (rat from the group with extrusive nutrition) shows only $\mathrm{s}$ diffuse distribution of damaged nerve cells surrounded by microglia in high-power field of brain tissue. Rat from the control group (standard food ration, figure from the left side) has the only one, in fact, region with neurons, surrounded by microglia.
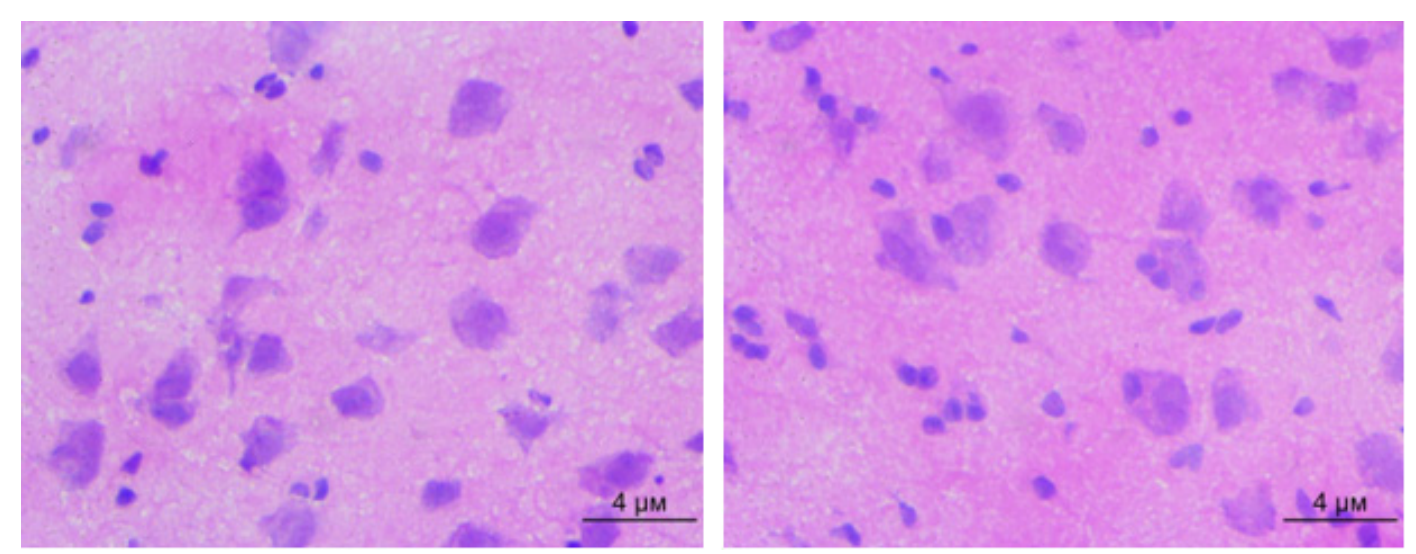

Figure 1: Rats' brain slices at the level of basal ganglia: on the left - from the first group with standard ration, on the right from the one with extrusive ration. Hematoxylin-eosin staining.

It was logical to assess and match microbiota state in rats from all three groups, because components of all food rations first of all contact gastrointestinal contents. Microbiota samples were sent to microbiological laboratory of the Institute of Physiology of National Academy of Sciences of Belarus. Bifid bacterium, Lactobacillus, Escherichia coli, Candida and Enterococcus were identified. Species identification and quantitative count of colony-forming units together with assessment of their morphological (microscopy) and biochemical properties were made after the incubation. Obtained result was described as common number logarithm. Microbiological analysis showed the fact of rapid disturbance in balance of all the groups of microorganisms in rats with extrusive nutrition. Taking into account latest beliefs on fatal outcomes of microbiota balance disturbance [9-11], which are implemented through complex hormonal and neurological pathways [12], it is quite reasonable to make a guess about the reasons of pathological changes in central nervous system, locomotor functions control, violation of body mass control in rats, receiving extrusion food products. The process of extrusion results in conformational changes of proteins $[6,8]$, leading to predictable changes in their functions. Acceptance of such proteins by microflora leads to change in functional activity of intestinal microorganisms. Microflora balance is violated. Endotoxins and other toxic products of intestinal microflora metabolism are excreted into internal milieu [13-17]. Mentioned in the article pathological changes in various functional systems of experimental animals are the consequences of such process. Therefore, certain extrusion food products act as specific trigger of pathological processes in the organism. Revealing the mechanism of these processes will allow implementing special preventive measures both on consumption stages and different stages of technological process.

\section{Conclusion}

Extrusion technology is considered one of the most perspective and highly effective, which involves thermal, hydro- and mechanical processing and allows obtaining next-gen products with predefined properties. However, compared to traditional technologies of food preparing, which have been tested for ages, it is useful to conduct insightful fundamental and applied studies which will allow defining and improving conditions of extrusion products preparing. It is also quite important to determine conditions when side effects of these products may manifest.

\section{Acknowledgement}

This pooled analysis was funded by 000 "Synergy", and by SPSI "Convergence"

\section{References}

1. Rosettie KL, Micha R, Cudhea F, Peñalvo JL, O Flaherty M, et al. (2018) Comparative risk assessment of school food environment policies and childhood diets, childhood obesity, and future cardiometabolic mortality in the United States. PLoS One 13(7): e0200378.

2. Mangen MJ, Bouwknegt M, Friesema IH, Haagsma JA, Kortbeek LM, et al. (2015) Cost-of-illness and disease burden of food-related pathogens in the Netherlands, 2011. Int J Food Microbiol 196: 84-93.

3. Chavan RB, Thipparaboina R, Yadav B, Shastri NR (2018) Continuous manufacturing of co-crystals: challenges and prospects. Drug Deliv Transl Res.

4. Stitt PA (1993) Fighting the Food Giants, Manitowoc, WI: Natural Press.

5. Llopart EE, Drago SR, De Greef DM, Torres RL, González RJ (2014) Effects of extrusion conditions on physical and nutritional properties of extruded whole grain red sorghum (sorghum spp). Int J Food Sci Nutr 65(1): 34-41. 
6. Patel JR, Patel AA, Singh AK (2016) Production of a protein-rich extruded snack base using tapioca starch, sorghum flour and casein. J Food Sci Technol 53(1): 71-87.

7. Bittner A, Cramer B, Harrer H, Humpf HU (2015) Structure elucidation and in vitro cytotoxicity of ochratoxin $\alpha$ amide, A new degradation product of ochratoxin A. Mycotoxin Res 31(2): 83-90.

8. Humpf HU, Voss KA (2004) Effects of thermal food processing on the chemical structure and toxicity of fumonisin mycotoxins. Mol Nutr Food Res 48(4): 255-269.

9. Biedermann L, Rogler G (2015) The intestinal microbiota: It's role in health and disease. Eur J Pediatr 174(2): 151-167.

10. Jahani-Sherafat S, Alebouyeh M, Moghim S, Ahmadi Amoli H, GhasemianSafaei H (2018) Role of gut microbiota in the pathogenesis of colorectal cancer: A review article. Gastroenterol Hepatol Bed Bench 11(2): 101109.

11. Carrera-Quintanar L, López Roa RI, Quintero-Fabián S, SánchezSánchez MA, Vizmanos B, et al. (2018) Phytochemicals That Influence Gut Microbiota as Prophylactics and for the Treatment of Obesity and Inflammatory Diseases. Mediators Inflamm 2018: 9734845.

\section{ISSN: 2574-1241}

DOI: 10.26717/BJSTR.2018.07.001503

Vladimir Kulchitsky. Biomed J Sci \& Tech Res

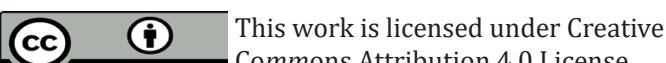

Submission Link: https://biomedres.us/submit-manuscript.php
12. Romieu I, Dossus L, Barquera S, Blottière HM, Franks PW, et al. (2017) Energy balance and obesity: What are the main drivers? Cancer Causes Control 28(3): 247-258.

13. Altamirano-Barrera A, Uribe $\mathrm{M}$, Chávez-Tapia NC, Nuño-Lámbarri $\mathrm{N}$ (2018) The role of the gut microbiota in the pathology and prevention of liver disease. J Nutr Biochem 60: 1-8.

14. Naito T, Mulet C, De Castro C, Molinaro A, Saffarian A (2017) Lipopolysaccharide from Crypt-Specific Core Microbiota Modulates the Colonic Epithelial Proliferation-to-Differentiation Balance. MBio 8(5): 80-117.

15. Romanovsky AA, Sugimoto N, Szekely M, Kulchitsky VA (1997) Febrile responsiveness of vagotomized rats is suppressed even in the absent of malnutrition. Am J Physiol 273: R777-R783.

16. Romanovsky AA, Ivanov AI, Lenczowski MJP, Kulchitsky VA, Van-Dam A-M, et al. (2000) Lipopolysacharide transport from the peritoneal cavity to the blood: Is it controlled by the vagus nerve? Autonom Neurosci 85(1-3): 133-140.

17. Koulchitsky SV, Kulchitsky VA (2001) Central and peripheral mechanisms of nociceptive reflexes in conditions of acute phase reaction. Proc Natl Sci Counc ROC(B) 25(4): 197-213.

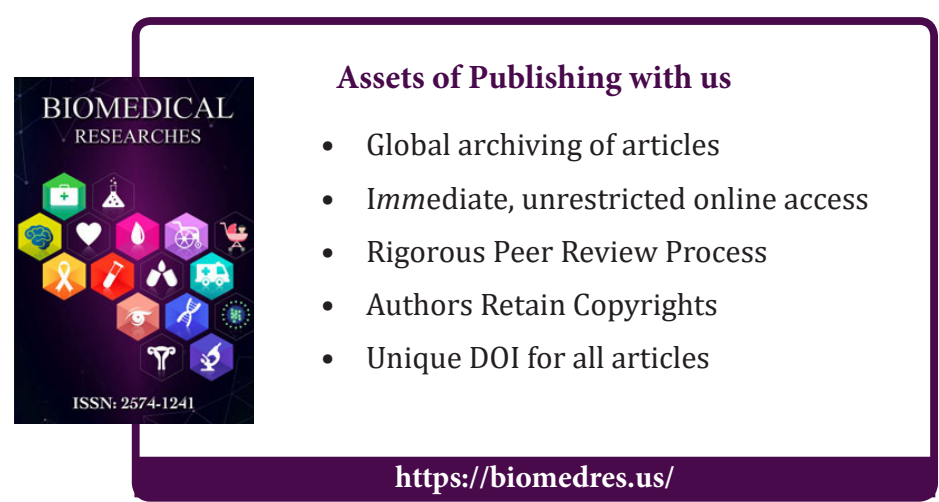

